\title{
Compelling Evidence for Lucky Survivor and Gas Phase Protonation: The Unified MALDI Analyte Protonation Mechanism
}

\author{
Thorsten W. Jaskolla, Michael Karas
}

Cluster of Excellence Macromolecular Complexes, Institute of Pharmaceutical Chemistry, Goethe University Frankfurt, Max-von-Laue-Str. 9, 60438, Frankfurt, Germany

\begin{abstract}
This work experimentally verifies and proves the two long since postulated matrix-assisted laser desorption/ionization (MALDI) analyte protonation pathways known as the Lucky Survivor and the gas phase protonation model. Experimental differentiation between the predicted mechanisms becomes possible by the use of deuterated matrix esters as MALDI matrices, which are stable under typical sample preparation conditions and generate deuteronated reagent ions, including the deuterated and deuteronated free matrix acid, only upon laser irradiation in the MALDI process. While the generation of deuteronated analyte ions proves the gas phase protonation model, the detection of protonated analytes by application of deuterated matrix compounds without acidic hydrogens proves the survival of analytes precharged from solution in accordance with the predictions from the Lucky Survivor model. The observed ratio of the two analyte ionization processes depends on the applied experimental parameters as well as the nature of analyte and matrix. Increasing laser fluences and lower matrix proton affinities favor gas phase protonation, whereas more quantitative analyte protonation in solution and intramolecular ion stabilization leads to more Lucky Survivors. The presented results allow for a deeper understanding of the fundamental processes causing analyte ionization in MALDI and may alleviate future efforts for increasing the analyte ion yield.
\end{abstract}

Key words: CHCA, CICCA, Deuteration, Deuteronation, Ester, Ionization, Matrix, Plume reactions, Proton transfer

\section{Introduction}

A lthough matrix-assisted laser desorption/ionization (MALDI) mass spectrometry (MS) [1-4] has found widespread use in the analysis of biological and biochemical samples, the essential analyte ionization step is not yet fully understood. Variations of experimentally accessible parameters

Electronic supplementary material The online version of this article (doi:10.1007/s13361-011-0093-0) contains supplementary material, which is available to authorized users.

Correspondence to: Thorsten Jaskolla; e-mail: Jaskolla@pharmchem. uni-frankfurt.de such as, e.g., laser fluence and irradiation wavelength as well as matrix and analyte properties led to a large variety of proposals and partial aspects regarding the underlying processes [2, 528]. For closer insights, the physicochemical reactions taking place were elucidated by determination of the gas phase basicities as well as proton and electron affinities of the involved matrix [29-36] and analyte [37-43] neutral and ion species and were complemented by theoretical considerations and computational chemistry [34, 44-49]. From these investigations, two conflicting theories predominantly discussed nowadays emerged: The Lucky Survivor theory $[17,50]$ and the gas phase protonation model $[5,16,24,28,51]$. Both will be briefly discussed in the following. 


\section{The Lucky Survivor Model}

The Lucky Survivor model postulates that analytes are incorporated in the matrix crystals with their respective charge states preserved from solution. At typical preparation conditions, peptides and proteins, the preferentially investigated analyte classes, are protonated and would therefore be incorporated as positively precharged analytes together with their counterions. Incorporation of analytes in their respective solution charge state could be confirmed by means of $\mathrm{pH}$ indicator probes [52] and adduct detection of precharged analytes with anions of extremely strong acids originating from solution [53, 54]. The original model differentiates between two possibilities: In the first case, ablated clusters generated upon laser irradiation contain precharged analytes with their corresponding amount of counterions and are therefore without net charge. Cluster dissociation induces entire charge neutralization or generation of net neutral adducts in the case of stable anions which both cannot be detected. In the second case, clusters carry a net charge initiated by charge separation upon disruption of the matrix-analyte solid. A lack of counterions inhibits quantitative charge neutralization and leads to protonated analytes. Provided that these ions are not neutralized by absorption of photoelectrons or electrons from the metallic target $[18,55,56]$, they can be detected as so-called Lucky Survivors.

However, the original Lucky Survivor model [17] had limitations in the description of analyte anion generation. Clusters with excess negative charges can quantitatively neutralize positively precharged analytes, but subsequent analyte deprotonation by counterion neutralization will be endergonic because the carboxylic acid groups of peptides and proteins are less acidic than common counterions such as trifluoroacetate or chloride. To account for this a refined Lucky Survivor model was developed [50], which postulates that matrix excess charges $[\mathrm{ma}+\mathrm{H}]^{+}$or $[\mathrm{ma}-\mathrm{H}]^{-}$included in the clusters lead to generation of protonated analytes by counterion neutralization or to analyte deprotonation, respectively. Matrix anions generally consist of carboxylates or delocalized phenolates whose neutralized counterparts exhibit about the same acidity as the analyte carboxylic acid groups. Consequently, analyte deprotonation should not be very efficient, which is in agreement with the typically low intense anionic analyte signals achievable using acidic matrices [26, 49].

\section{The Gas Phase Protonation Model}

This model predicts neutral analytes in the gas phase originating either from incorporation in the matrix crystals as uncharged species or from quantitative charge recombination with the respective counterions in the case of precharged analytes. Gas phase collisions of neutral analytes with protonated $[\mathrm{ma}+\mathrm{H}]^{+}$or deprotonated $[\mathrm{ma}-\mathrm{H}]^{-}$matrix ions lead to proton transfer reactions and to protonated or deprotonated analytes, respectively [16, 24, 51].

Both models, the refined Lucky Survivor model as well as the gas phase protonation model, comprise the necessity of protonated matrix ions $[\mathrm{ma}+\mathrm{H}]^{+}$for analyte protonation. This is in agreement with the results of Land and Kinsel [14], who proved a correlation between the matrix radical cation intensity as assumed precursor species for $[\mathrm{ma}+\mathrm{H}]^{+}$ according to Equation 1, [5] and the intensity of protonated analytes.

$$
\mathrm{ma}^{\bullet+}+\mathrm{ma} \rightarrow[\mathrm{ma}-\mathrm{H}]^{\bullet}+[\mathrm{ma}+\mathrm{H}]^{+}
$$

In addition, quenching of matrix ions at the expense of analyte protonation (also called the "matrix suppression effect" $[15,57]$ ) could be detected by means of angular and time resolved intensity distributions of matrix and analyte ions [6, 7]. However, despite numerous investigations and indications regarding the analyte protonation, the final elucidation of the actual mechanism is still missing.

\section{Experimental}

\section{Materials and Reagents}

$\alpha$-Cyano-4-hydroxycinnamic acid (CHCA [58]) was purchased from Bruker Daltonics (Bremen, Germany), acetonitrile (ACN, Rotisolv HPLC gradient grade) was from Roth (Karlsruhe, Germany), and p-anisaldehyde (99+\%) was obtained from Acros (Nidderau, Germany). MilliQ water was prepared by a Millipore (Schwalbach, Germany) water purification system. The peptides ITITPNK and ITITPNV were obtained from the Central Peptide Synthesis Unit of the German Cancer Research Center (DKFZ). All other chemicals were purchased from Sigma-Aldrich (Taufkirchen, Germany) and were of the highest grade available.

\section{Synthesis of Undeuterated and Deuterated Matrix Esters}

In a first step, cyanoacetic acid was esterified to cyanoacetic acid-tert-butylester- $\mathrm{d} 9$ according to the synthesis route given by Neises and Steglich [59]. Briefly, 1 eq cyanoacetic acid was dissolved in sufficient amounts of dry $\mathrm{CH}_{2} \mathrm{Cl}_{2} / \mathrm{ACN}$ $(1: 3, \mathrm{vol} / \mathrm{vol})$. Upon addition of 0.07 eq 4-dimethylaminopyridine and 1.25 eq tert-butanol-d10, the reaction mixture was cooled to $0{ }^{\circ} \mathrm{C}$ and 1.1 eq dicyclohexylcarbodiimid were added at small portions. After stirring for $5 \mathrm{~min}$, the ice was removed and the reaction was stirred further $20 \mathrm{~min}$ at room temperature. After removing solid byproducts by filtration, the solvent was evaporated and the crude tert-butylcyanoacetate-d 9 was purified by short-path distillation at $12 \mathrm{mbar}$ and $84{ }^{\circ} \mathrm{C}$. Yield: $68 \%$ of the theoretical value as clear oil. For subsequent syntheses of the $\alpha$-cyanocinnamic acid ester derivatives, Knoevenagel condensation reactions using the 
deuterated or undeuterated cyanoacetic acid esters and the respective benzaldehyde (4-hydroxybenzaldehyde or 4chlorobenzaldehyde) were performed according to the instructions given in the literature [60]. Yields for the cyanocinnamic acid ester syntheses were between $82 \%$ $95 \%$ as white (4-chloro- $\alpha$-cyanocinnamic acid (ClCCA [28])-ester) to yellow (CHCA-esters) crystals.

\section{Sample Preparation and Measurement}

Polished stainless steel substrates and standard dried droplet preparations were used for all experiments. For the MS and MS/MS matrix spectra, $0.5 \mu \mathrm{L}$ of matrix solution $(20 \mathrm{mM}$, $70 \%$ ACN) were spotted onto a target and air dried. For experiments applying analytes, mixtures of $0.5 \mu \mathrm{L}$ of the matrix solution $(20 \mathrm{mM}, 70 \% \mathrm{ACN})$ and $1 \mu \mathrm{L}$ of the analyte solution $(10 \mu \mathrm{M}, 30 \% \mathrm{ACN} / 0.1 \% \mathrm{TFA}$ in the cases of the peptides ITITPNK and ITITPNV, $100 \mu \mathrm{M}$ in all other cases) were spotted without premixing onto a target and air dried. Possible additions of acid or base are indicated at the appropriate places in the text. The reason for the comparably high analyte amounts required for the neutral matrix esters is assumed to be the lacking ion-pair formation possibility between deprotonated matrix and protonated analyte ions, which is hypothesized to be crucial for effective analyte incorporation [28].

\section{Mass Spectrometry}

All MALDI MS measurements were carried out using a standard Voyager DE-STR TOF mass spectrometer (Applied Biosystems, Darmstadt, Germany) with a VSL-33737ND $337 \mathrm{~nm}$ nitrogen laser (LSI Laser Science, Newton, MA, USA) producing 3 ns laser pulses with a pulse repetition rate of $20 \mathrm{~Hz}$ and an approximately circular spot size of 50 $100 \mu \mathrm{m}$ in diameter. For pure CHCA as well as undeuterated and deuterated CHCA- and ClCCA-ester spectra, 10 single mass spectra with 500 laser shots each were accumulated. Also, for the experiments using the glycine monomer, dimer, and hexamer as well as the peptides ITITPNK and ITITPNV as analytes, all measurements were repeated 10-fold with 500 laser shots each. For all other mass spectra, four mass spectra with 500 laser shots each were accumulated. Laser fluences optimized for highest analyte $\mathrm{S} / \mathrm{N}$ ratios were used for all approaches comprising analytes in which the absolute energy is not indicated. The optimum pulse energies were determined to about $1.5 \mu \mathrm{J} /$ pulse for $\mathrm{CHCA}$, undeuterated and deuterated CHCA-tert-butylester and to about $1.9 \mu \mathrm{J} /$ pulse for ClCCA-tert-butylester-d9 using a calibrated energy probe (Nova laser power/energy meter; Ophir Optronics, Grosshansdorf, Germany) with a low-energy pyroelectric photodiode PE10 inserted in the laser beam path before entrance into the vacuum of the mass spectrometer. For analyzing pure matrices, the laser fluences were lowered by about $0.4 \mu \mathrm{J}$ for all used compounds, which were still about $10 \%$ above the respective threshold. Typical MALDI-TOF parameter settings for standard MS measurements were chosen and were polarity, positive; operation mode, reflector; accelerating voltage, $20 \mathrm{kV}$; grid voltage, $70 \%$; low mass gate, off; delay time, $150 \mathrm{~ns}$; shots per spectrum, 500; time resolution, $0.5 \mathrm{~ns}$. For the peptides ITITPNK and ITITPNV, the grid voltage was set to $68.5 \%$ and the low mass gate to $550 \mathrm{Da}$. Data Explorer 4.5 (Applied Biosystems, Darmstadt, Germany) was used for analysis of the spectra. Peak detection was performed by using a $\mathrm{S} / \mathrm{N}$ threshold of 10 after external calibration and advanced baseline correction with preset parameters. The chosen parameters for the MS/MS fragmentation of the CHCAtert-butylester were as follows: laser fluence, $1.2 \mu \mathrm{J} / \mathrm{pulse}$; polarity, positive; operation mode, reflector; accelerating voltage, $20 \mathrm{kV}$; grid voltage, $68.5 \%$; delay time, $150 \mathrm{~ns}$; low mass gate, off; bin size, 0.5 ns; shots per segment, 500; precursor mass, $246 \mathrm{Da}$; post-source decay (PSD) mirror ratios, 1, 0.8, 0.75, and 0.5; guide wire for all segments, $0.05 \%$.

The CHCA-tert-butylester-d9 degree of deuteration was determined using a modified ESI orthogonal time-of-flight mass analyzer (Mariner; Applied Biosystems, Framingham, MA, USA) equipped with a nanoelectrospray source and a heated transfer capillary. The mass spectra of the deuterated ester ( $2 \mathrm{mM}$ in $80 \% \mathrm{ACN} / 0.1 \% \mathrm{TFA}$ ) were acquired in positive ion polarity for one minute at a spray potential of $800 \mathrm{~V}$ and a nozzle potential of $50 \mathrm{~V}$. The temperature of the transfer capillary was set to $180{ }^{\circ} \mathrm{C}$.

\section{Results and Discussion}

\section{Discrimination Between Lucky Survivor and Gas Phase Protonation}

Discrimination between the Lucky Survivor and gas phase protonation theory should be possible provided the matrix only delivers deuteronated matrix ions $[\mathrm{ma}+\mathrm{D}]^{+}$for gas phase ionization processes. According to the gas phase protonation model, this will lead to deuteronation instead of protonation of the uncharged analyte A (see Scheme 1, first row). In case of the validity of the Lucky Survivor model and positively precharged analytes $\mathrm{AH}_{\mathrm{n}}{ }^{\mathrm{n}+}$ with the corresponding counterions $\mathrm{nX}^{-}$, protonated analytes can be expected also in presence of deuteronated matrix ions either by incomplete charge neutralization during cluster generation and/or cluster decomposition or as a result of counterion neutralization by $[\mathrm{ma}+\mathrm{D}]^{+}$leading to the generation of neutral DX (see Scheme 1, second and third row). Therefore, validation of the proposed models would be directly possible by screening the mass spectra for the presence of either $[\mathrm{A}+\mathrm{H}]^{+}$or $[\mathrm{A}+\mathrm{D}]^{+}$.

For this purpose, a deuterated matrix compound, which enables exclusive generation of $[\mathrm{ma}+\mathrm{D}]^{+}$is necessary. According to Equation 1, generation of $[\mathrm{ma}+\mathrm{D}]^{+}$requires transfer of a $\mathrm{D}^{+}$from a deuterated matrix radical cation $\mathrm{ma}^{*+}$ to a neutral matrix molecule. Polarized bonds as present in, 


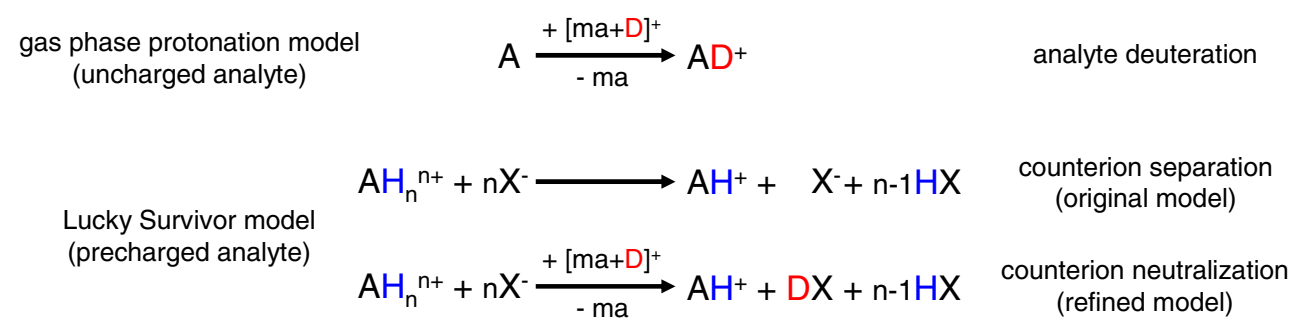

Scheme 1.

e.g., deuterated hydroxyl- (-OD) or carboxylic acid (-COOD) groups will strongly alleviate bond breaking with transfer of $\mathrm{D}^{+}$compared with nonpolar $\mathrm{C}-\mathrm{D}$ bonds. Therefore, pronounced $[\mathrm{ma}+\mathrm{D}]^{+}$generation necessitates matrix compounds with, e.g., deuterated hydroxyl- and/or carboxylic acid groups. However, such deuterations are instable during conventional dried droplet (DD) sample preparation due to $\mathrm{D} / \mathrm{H}$-exchange reactions in protic solvents, with analyte functionalities or also the humidity of the air. The use of deuterated solvents for avoiding loss of matrix deuteration will cause at least partial H/D exchanges of the analyte which has to be prevented since in this case the origin of analyte deuteration cannot be unequivocally determined. Consequently, the strategy was to synthesize deuterated matrix compounds without solution-phase $\mathrm{D} / \mathrm{H}-$ exchange by using stable $\mathrm{C}-\mathrm{D}$ bonds. Upon excitation by laser irradiation, the matrix to synthesize has to undergo a rearrangement leading to the generation of polarized -OD or - COOD groups for subsequent generation of $[\mathrm{ma}+\mathrm{D}]^{+}$.

\section{A Matrix for Exclusive Generation of the Deuteronated Matrix Species $[\mathrm{ma}+\mathrm{D}]^{+}$}

From experiments carried out earlier in the systematic investigation of the role of functional groups on matrix properties of $\alpha$-cyanocinnamic acid derivatives [28], we recollected that matrix esters typically yield two prominent ion signals, which are the protonated intact molecule and the protonated free acid as a fragment ion. Fragmentation of the ester to the acid can be proven by PSD analysis of the protonated ester, which yields nearly exclusive generation of the protonated free CHCA acid (compare Supplemental Information (SI) Figure 1 for the PSD spectrum of protonated CHCA-tert-butylester). It was tested whether a matrix ester, which is per-deuterated at the ester group, behaves in the expected way, thus forming the discriminating test reagent matrix needed. A possible contamination by the free matrix acid as a synthesis byproduct can be easily detected or excluded by the inspection of the ester mass spectra since present free acids will produce radical molecular ions, see SI Figure 2. The low-resolved signal shifted to a somewhat higher $\mathrm{m} / \mathrm{z}$-range in SI Figure $2 \mathrm{~b}$ cannot be detected in the upper spectrum of the free acid and is most probably due to PSD generated matrix acid from the matrix ester after ion acceleration. Similar low-resolved signals can also be detected for all other investigated esters. This suggests that the ester fragmentation is not finished until acceleration voltage is applied but already begins in the very early phase of the expanding plume. For more detailed discussion concerning the matrix ester fragmentation see SI Data 1.

For generation of the deuterated acid CHCA-COOD and its deuteronated counterpart [CHCA-COOD $+\mathrm{D}^{+}$ the CHCA-tert-butylester-d $9 \quad\left(\mathrm{MW}_{\text {neutral, }}\right.$ monoisotopic $=$ $254.16 \mathrm{~g} / \mathrm{mol}$ ) was synthesized and its mass spectrum was compared with that of the undeuterated CHCA-tert-butylester $\left(\mathrm{MW}_{\text {neutral, }}\right.$ monoisotopic $\left.=245.10 \mathrm{~g} / \mathrm{mol}\right)$, see Figure 1 . In Figure 1a, the protonated CHCA-tert-butylester and the corresponding fragment ion, the protonated $\mathrm{CHCA}$ acid at $m / z=190.05$, can be detected. Figure $1 \mathrm{~b}$ refers to the deuterated ester and exhibits a signal at $m / z=256.18$, which correlates to the deuteronated ester [CHCA-tert-butylester- $\mathrm{d} 9+\mathrm{D}]^{+}$and its fragment ion at $m / z=192.06$ representing the desired deuterated and deuteronated free acid [CHCA-COOD $+\mathrm{D}]^{+}$. A small amount of the d8-compound is indicated by the low-intensity signals at $m / z=255.17$ and $m / z=191.06$ in Figure $1 \mathrm{~b}$ and is caused by incomplete deuteration of the tert-butyl group as verified by ESI-MS (SI Figure 3). The deuteronated ester [CHCA-tert-butylester-d9 $+\mathrm{D}]^{+}$should also be able to deuteronate analytes although its reactivity is somewhat lowered compared with the deuteronated acid. Regarding the discussed need for exclusive generation of deuteronated matrix ions to verify gas phase analyte deuteronation, also the $[\mathrm{CHCA} \text {-tert-butylester-d9 }+\mathrm{D}]^{+}$fulfills this necessity.

The only source of deuterons for generation of the deuteronated tert-butylester- $\mathrm{d} 9$ and subsequently for the deuteronated acid [CHCA-COOD $+\mathrm{D}]^{+}$is the deuterated ester group. For energetic reasons, it could be expected that the CHCA-tert-butylester-d9 radical cation transfers a proton from the 4-hydroxyl group instead of a deuteron from a more stable $\mathrm{C}-\mathrm{D}$ bond of the ester group. Nevertheless, deuteron abstraction could cause a subsequent loss of isobutene-d8 and generation of $[\mathrm{CHCA}-\mathrm{H}]^{\circ}$ according to Equation 1. Although the exact reasons are not known in detail, it can be assumed that abstraction of a deuteron is energetically favored due to entropy and/or that the larger surface of the tert-butyl group compared with the hydroxyl group increases the probability for deuteron abstraction instead of that of a proton. Consequently, the missing 

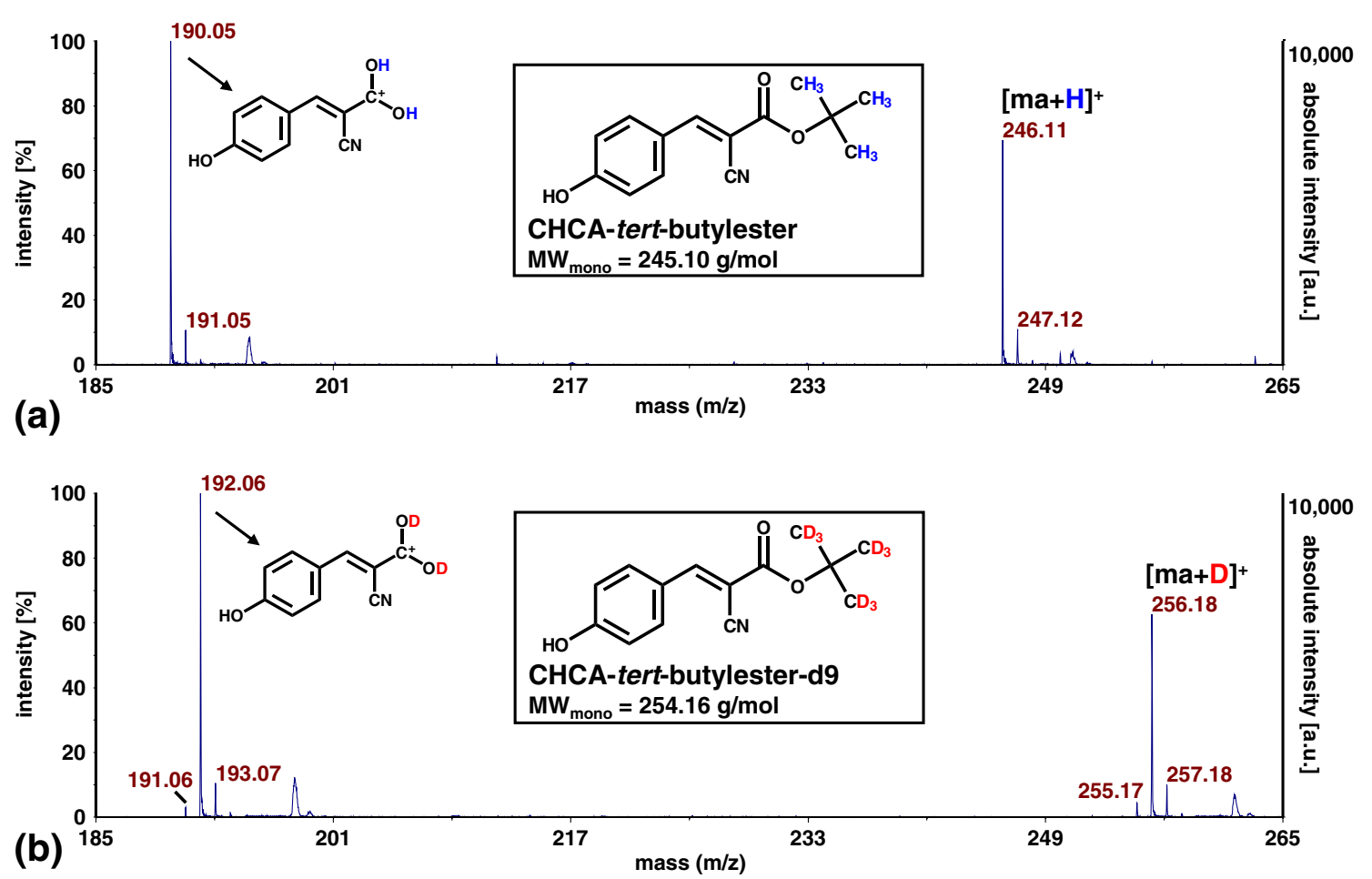

Figure 1. Positive-ion mode spectrum of $10 \mathrm{nmol}$ (a) CHCA-tert-butylester and (b) CHCA-tert-butylester-d9, respectively. Identical parameters were used for recording the matrix spectra

detectability of the ester radical cations in the mass spectra of Figure 1 might be explained by a high efficiency of this reaction. In order to completely exclude the involvement of the hydroxyl-hydrogen and to verify the role of matrix proton affinity [28], ClCCA-tert-butylester-d9 was synthesized as a second deuterated test matrix. It was not determined whether gas phase protonations and deuteronations exhibit identical reaction rates.

\section{Neutral Analytes $A$}

In a first case, neutral analytes A were used for investigating the MALDI analyte protonation mechanism by means of p-anisaldehyde (p-methoxybenzaldehyde) and 4'-hydroxyacetophenone. Matrix effects such as photoionization of the used analytes can be excluded due to their very low extinction coefficients at $337 \mathrm{~nm}$ and much lower concentrations compared with the used matrices CHCA-tert-butylester-d9 and its undeuterated counterpart. Since neutral analytes are incorporated without charges, only the gas phase protonation model is applicable to explain protonation of neutral analytes. Provided the correctness of this model, it can be expected that application of the undeuterated and deuterated CHCA-tertbutylester matrix cause protonation or deuteronation of the neutral analytes, respectively. In agreement with this, Figure 2a shows the protonated acid $[\mathrm{CHCA}+\mathrm{H}]^{+}$generated upon fragmentation of the undeuterated CHCA-tert-butylester together with the protonated analyte $[\mathrm{p} \text {-anisaldehyde }+\mathrm{H}]^{+}$at $\mathrm{m} / \mathrm{z}=137.06$. Contrary to this, the deuterated and deuteronated matrix acid [CHCA-COOD $+\mathrm{D}]^{+}$and the deuteronated analyte [p-anisaldehyde $+\mathrm{D}]^{+}$at $m / z=138.07$ can be detected in Figure $2 b$. The given close-ups substantiate either exclusive analyte protonation or deuteronation according to the postulation of the gas phase protonation model. In agreement with SI Figure 4 yielding comparable results with 4 '-hydroxyacetophenone as neutral analyte, this confirms the correctness of the gas phase protonation model.

\section{Medium Basic Analytes $\mathrm{A} /[\mathrm{A}+\mathrm{H}]^{+}$}

Medium basic analytes can exist as neutral as well as protonated species depending on the $\mathrm{pH}$ of the sample preparation solution. According to experiments regarding the incorporation of $\mathrm{pH}$-dependent dyes [52] or incorporation of stable adducts between protonated analytes and anions of extremely strong acids [53, 54], the incorporated analytes maintain their respective solution charge states within the matrix crystal. Therefore, it is reasonable to assume that medium basic analytes are incorporated both as neutral and protonated species in the matrix crystal in dependence of the $\mathrm{pH}$ conditions during crystallization. In a first approach, nicotinamide (niacinamide, $\mathrm{MW}_{\text {neutral, monoisotopic }}=122.05 \mathrm{~g} / \mathrm{mol}$ ) with a pKa value of 3.4 [61] was used as medium basic analyte together with the undeuterated neutral matrix CHCA-tertbutylester at neutral $\mathrm{pH}$ values, see SI Figure 5. Under these conditions, the vast majority of nicotinamide exists as uncharged species, however, a small amount is still protonated. No acid was added to the preparation solution to avoid influence 


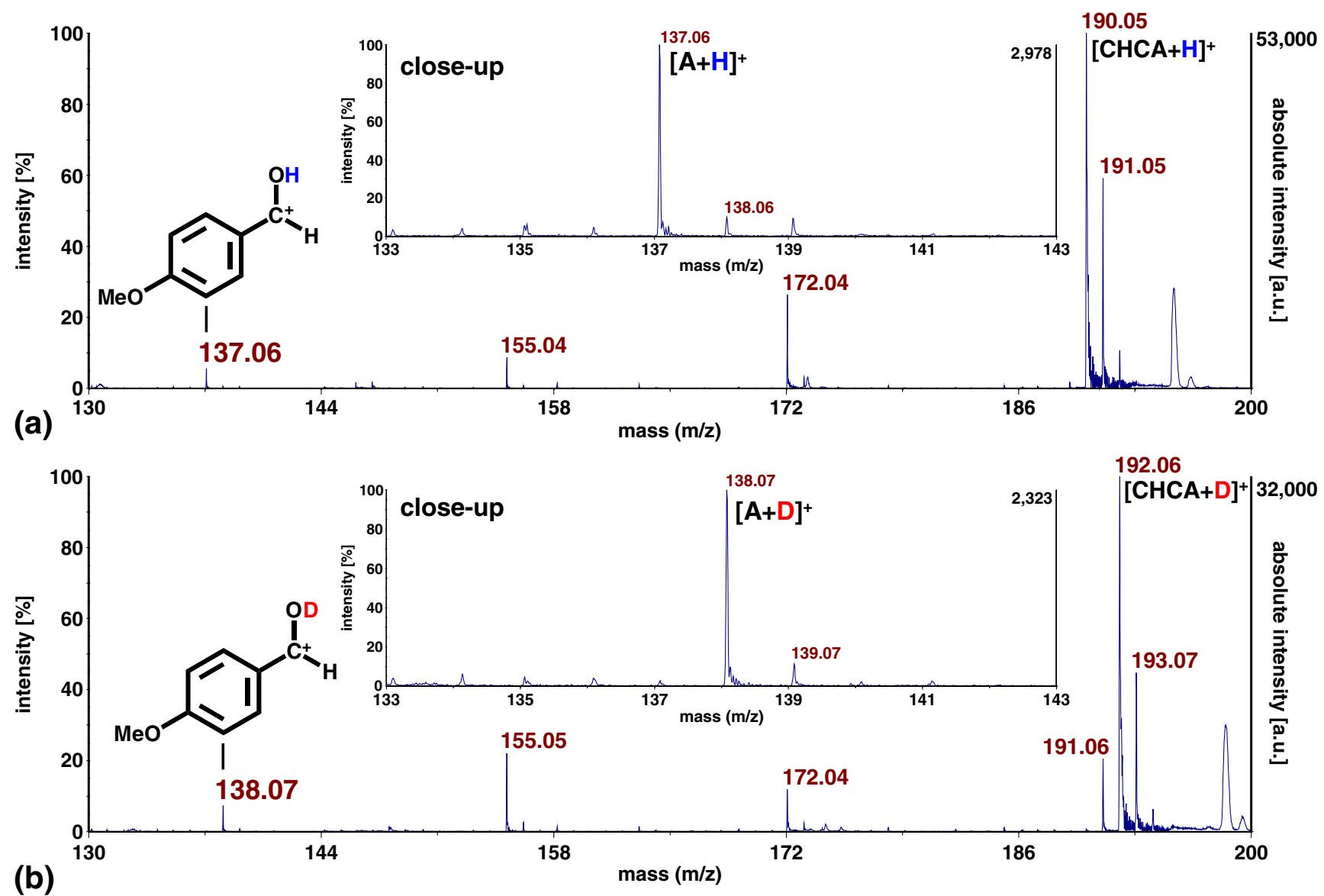

Figure 2. Protonation and deuteronation of the neutral analyte $\mathrm{p}$-anisaldehyde ( $\mathrm{MW}=136.15 \mathrm{~g} / \mathrm{mol}) \mathrm{using}$ the matrix (a) $\mathrm{CHCA}$-tert-butylester or (b) CHCA-tert-butylester-d9, respectively. Please remember that the monoisotopic peaks of [CHCA$\mathrm{COOH}+\mathrm{H}]^{+}$and $[\mathrm{CHCA}-\mathrm{COOD}+\mathrm{D}]^{+}$are saturated in some of the single spectra accumulated for Fig. 2 . The insets show a close-up of the analyte $\mathrm{m} / \mathrm{z}$ range. Identical parameters were used for recording the spectra

of the neutral-to-protonated analyte ratio $\mathrm{A} /[\mathrm{A}+\mathrm{H}]^{+}$. As can be seen in SI Figure 5a, nicotinamide can be detected exclusively as protonated species at $\mathrm{m} / \mathrm{z}=123.06$ together with the protonated acid [CHCA-COOH $+\mathrm{H}]^{+}$generated upon fragmentation of the undeuterated CHCA-tert-butylester. Subsequently, nicotinamide was used together with the deuterated matrix ClCCA-tert-butylester-d9 for SI Figure $5 \mathrm{~b}$. In this case, not only the protonated but also the deuteronated nicotinamide can be detected at $m / z=123.06$ and 124.06 , respectively. Additionally, the deuterated and deuteronated acid [ClCCA-COOD $+\mathrm{D}]^{+}$is detected at $\mathrm{m} / \mathrm{z}=210.03$ and 212.03 as the main fragment ion of the deuterated ClCCAtert-butylester-d9. Generation of the protonated as well as deuteronated nicotinamide can be explained by Scheme 2: Both neutral and protonated nicotinamide is incorporated in the matrix crystals. In accordance with previously discussed deuteronation of neutral analytes, the neutral portion of nicotinamide can undergo gas phase deuteronation to $[\mathrm{A}+\mathrm{D}]^{+}$according to the gas phase protonation model. However, the protonated nicotinamide percentage originating from the preparation solution gets detectable as $[\mathrm{A}+\mathrm{H}]^{+}$upon anion neutralization or -separation corresponding to the Lucky Survivor model. Application of the undeuterated CHCA-tert-butylester only leads to the exclusive generation of protonated nicotinamide $[\mathrm{A}+\mathrm{H}]^{+}$ although two different ionization pathways are involved.

The reason for using the ClCCA-tert-butylester-d9 instead of the CHCA-analog was to avoid the possibility of $\mathrm{D} / \mathrm{H}$-exchange reactions between deuteronated nicotinamide

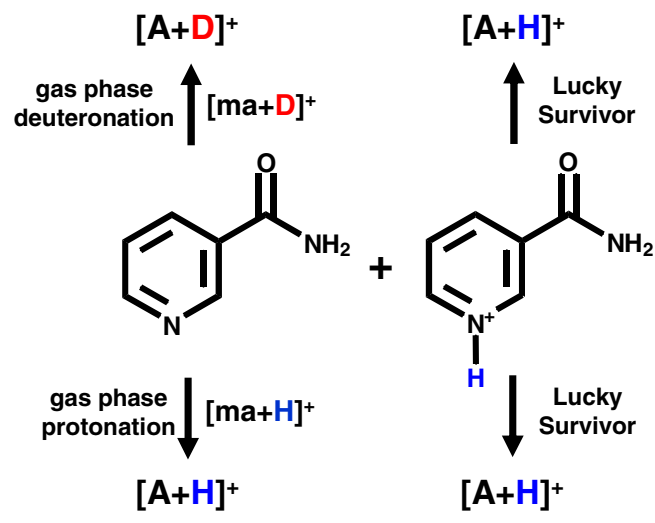

Scheme 2. 
$[\mathrm{A}+\mathrm{D}]^{+}$and the 4-hydroxyl group of the CHCA matrix as alternative explanation for generation of the protonated nicotinamide. Although such $\mathrm{D} / \mathrm{H}$-exchanges could not be detected for the previously discussed deuteronated analytes p-anisaldehyde or 4'-hydroxyacetophenone using CHCAtert-butylester-d9, application of ClCCA-tert-butylester-d9 clearly proves the existence of the Lucky Survivor process since no acidic hydrogens are available in ClCCA-tertbutylester-d9 or [ClCCA-COOD $+\mathrm{D}]^{+}$capable of explaining an alternative generation of $[\mathrm{A}+\mathrm{H}]^{+}$.

Simultaneous detection of protonated and deuteronated medium basic analytes by means of parallel Lucky Survivor and gas phase protonation or deuteronation in the case of deuterated matrices, respectively, allows for investigation of the parameters influencing each ionization pathway. Variation of the $\mathrm{pH}$ value during sample preparation leads to increased or decreased amounts of protonated analytes and therefore to a promotion or suppression of the Lucky Survivor process. Figure $3 \mathrm{a}$ demonstrates the influence of $\mathrm{pH}$-variation for the medium basic analyte nicotinamide and the deuterated matrix ClCCA-tert-butylester-d9 (top: addition of one $\mu \mathrm{L} 0.1 \mathrm{M} \mathrm{NaOH}$ and bottom: one $\mu \mathrm{L} 1 \%$ TFA solution to the DD preparation, respectively). No radical cations of the corresponding matrix acids could be detected in the mass spectra upon base or acid addition thereby proving that no ester cleavage occurred in solution during sample preparation. With decreasing $\mathrm{pH}$ value, the percentage of nicotinamide incorporated in the matrix crystals as protonated species increases, leading to an activation of the Lucky Survivor and to an increase of $[\mathrm{A}+\mathrm{H}]^{+}$at $m / z=$ 123.06 compared with $[\mathrm{A}+\mathrm{D}]^{+}$originating from gas phase deuteronation, see Figure 3 a.

Activation of the gas phase protonation process requires higher amounts of the protonating matrix species $[\mathrm{ma}+\mathrm{H}]^{+}$ or $[\mathrm{ma}+\mathrm{D}]^{+}$in the case of analyte deuteronation, respectively. According to Equation 1, the yield of these matrix ions depends on the amount of matrix radical cations, which in turn depends on the applied laser fluence. Increase of the laser fluence, consequently, activates gas phase deuteronation as is verified by the mass spectra of Figure 3b, which are

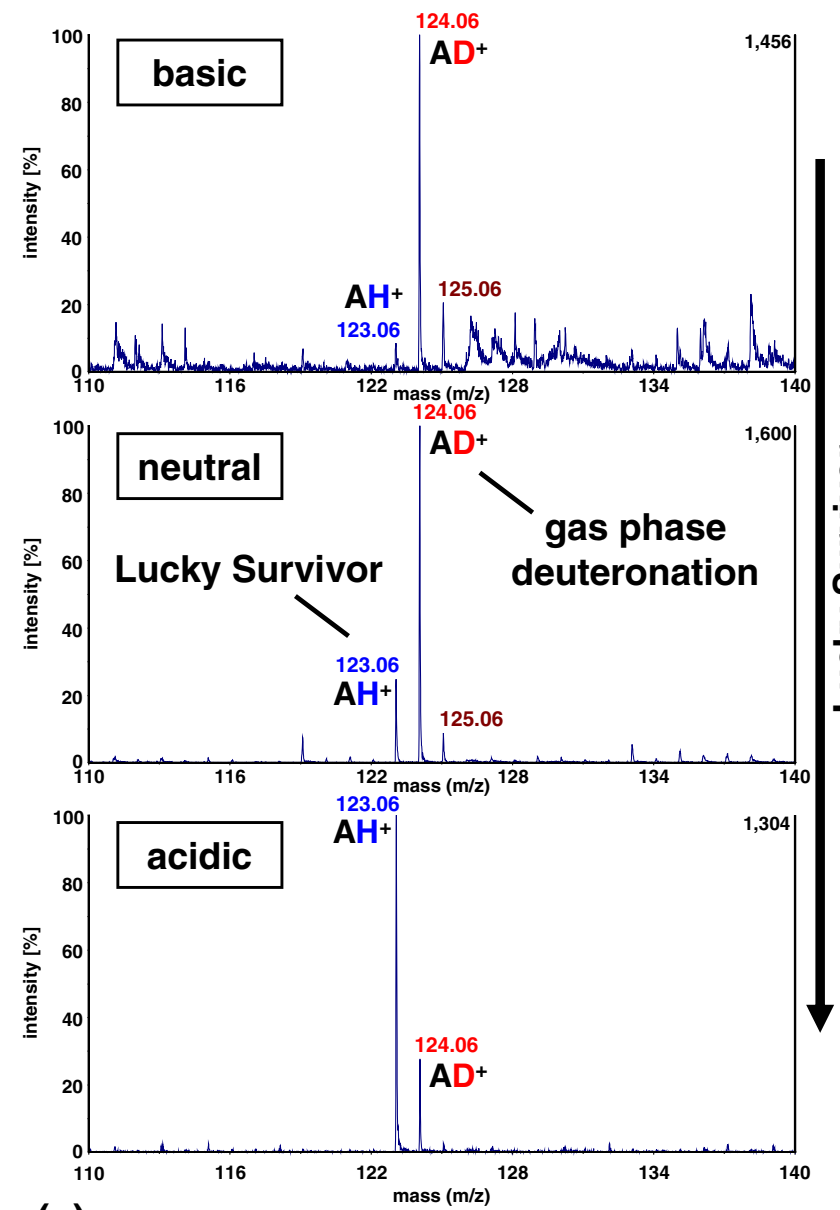

(a)

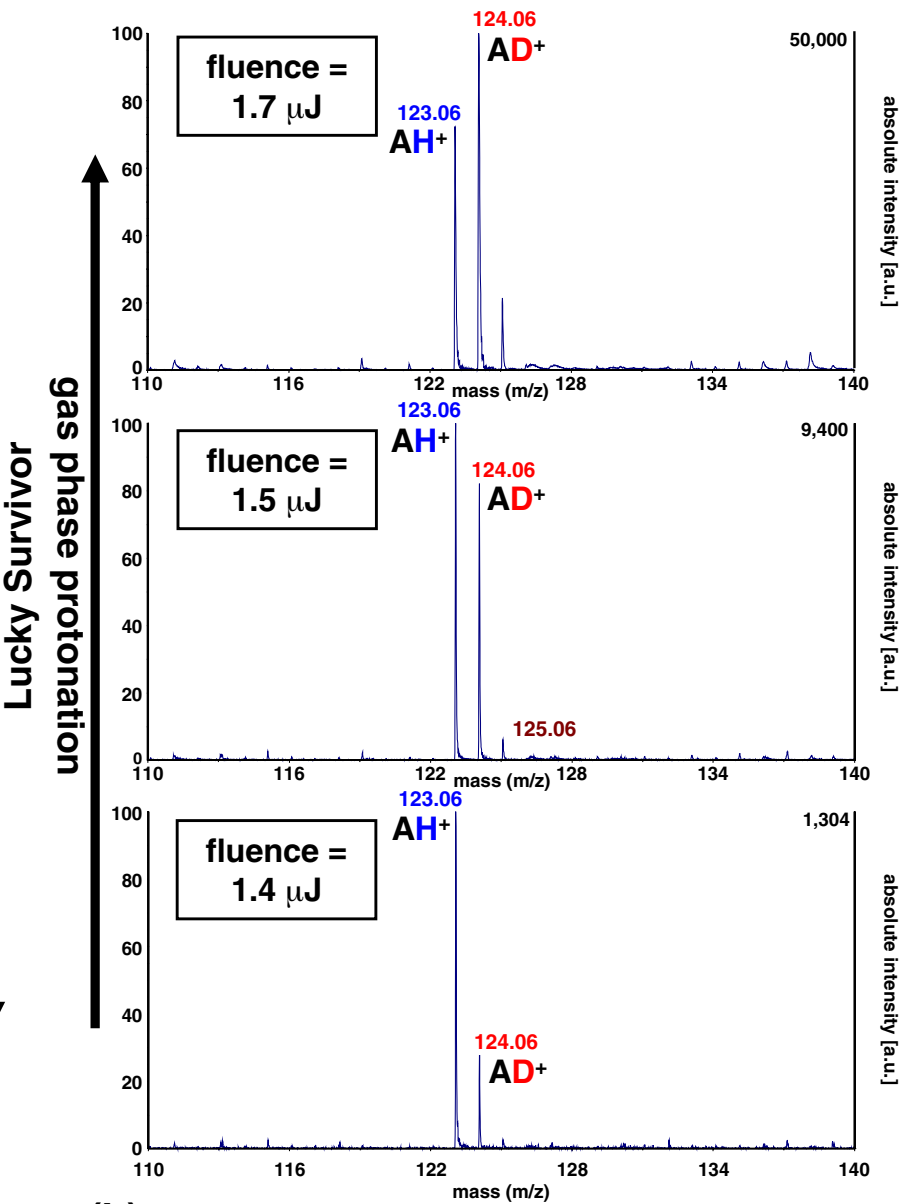

(b)

Figure 3. Promotion and suppression of Lucky Survivor and gas phase protonation, respectively. (a) Influence of the analyte protonation state using different solvent $\mathrm{pH}$ values at a laser fluence of $1.4 \mu \mathrm{J}$. (b) Influence of the laser fluence at acidic conditions. CICCA-tert-butylester-d9 and nicotinamide have been used as matrix and analyte, respectively. One $\mu \mathrm{L} 1 \%$ (vol/vol) TFA or $1 \mu \mathrm{L} 0.1 \mathrm{M} \mathrm{NaOH}$ solution were added to the DD-preparation for acidic or basic conditions 
all recorded at acidic conditions. With increased laser fluence going along with stronger formation of $[\mathrm{ma}+\mathrm{D}]^{+}$ions, an increase in deuteronated nicotinamide $[\mathrm{A}+\mathrm{D}]^{+}$is observed. The absolute intensity of $[\mathrm{A}+\mathrm{H}]^{+}$also increases with rising laser fluence, which can be traced back to a stronger ablation of matrix material with embedded precharged analytes $[\mathrm{A}+\mathrm{H}]^{+}$leading to a more intense counterion separation and/or to a more efficient counterion neutralization of $[\mathrm{A}+\mathrm{H}]^{+}$by $[\mathrm{ma}+\mathrm{D}]^{+}$. Thus, also the contribution of the Lucky Survivor mechanism increases upon higher laser fluences, although the gain is less pronounced than in the case of gas phase protonation or deuteronation.

We therefore conclude that the nature of the analyte (basicity) as well as the preparation and measurement conditions ( $\mathrm{pH}$ and laser fluence) determines the dominant analyte protonation pathway which, however, is not discernible in normal MALDI mass spectrometric experiments.

\section{Basic (Positively Precharged) Analytes $[\mathrm{A}+\mathrm{H}]^{+}$}

The overwhelming majority of analytes investigated with MALDI MS are peptides and proteins. It was therefore of interest whether the Lucky Survivor or the gas phase protonation process is the dominant ionization pathway for these analyte classes.

For this purpose, the basic peptide ITITPNK ( $\mathrm{pI}=10.1$ [62], Figure 4) and the nearly neutral peptide ITITPNV ( $\mathrm{pI}=6$ [62], SI Figure 6) were used as analytes and measured with the undeuterated matrix CHCA-tert-butylester and the deuterated matrices CHCA-tert-butylester-d9 as well as ClCCA-tertbutylester-d9. For mimicking typically used acidic preparation conditions and matrices, $0.1 \%$ TFA was added to the preparation solutions. The detected differences in absolute ion intensities between CHCA-tert-butylester and its deuterated counterpart are most probably due to different crystal morphologies as all parameter settings, including laser fluence and matrix and analyte amounts, were identical. In the case of the undeuterated CHCA-tert-butylester both analyte ionization pathways result in generation of $[\mathrm{A}+\mathrm{H}]^{+}$without differentiation possibility, see Figure $4 \mathrm{a}$ and SI Figure $6 \mathrm{a}$. The insets show the calculated isotope ratios of the respective protonated analytes, which are in good agreement with the measured ones. At typically used preparation conditions comprising acidic matrices and addition of, e.g., $0.1 \%$ TFA, even acidic peptides and proteins are nearly quantitatively protonated in solution. Using the deuterated matrix CHCA-tert-butylester-d9, strong signals of the protonated analytes $[\mathrm{A}+\mathrm{H}]^{+}$can still be detected which are in agreement with the Lucky Survivor process, see

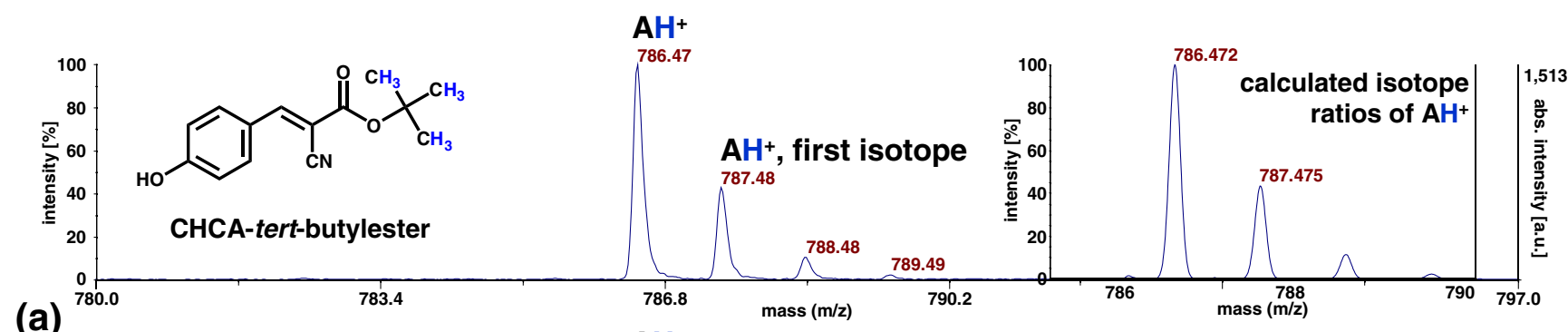

(a)

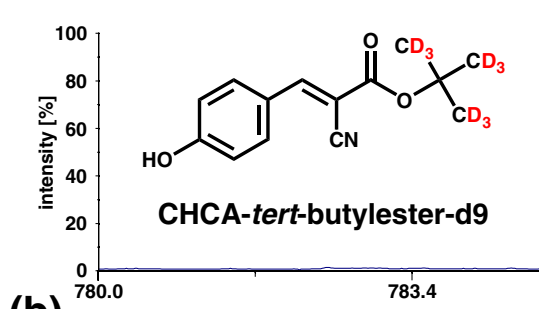

(b)

$\mathbf{A H}^{+}$
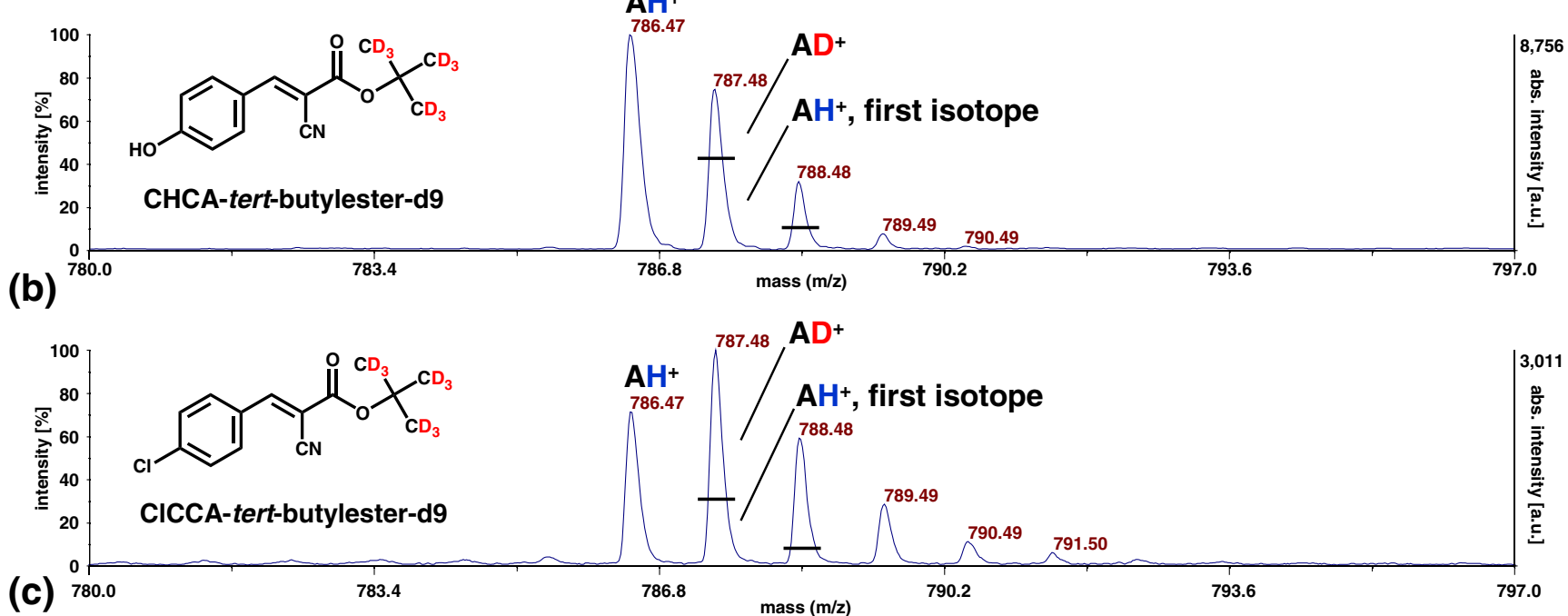

Figure 4. Intensities of the protonated and deuteronated signals of the peptide ITITPNK abbreviated as "A" by using the (a) undeuterated and (b) deuterated CHCA-tert-butylester as well as (c) the more reactive deuterated CICCA-derivative. Inset: calculated isotope ratios of protonated ITITPNK. The horizontal lines represent the isotope intensities of $\mathrm{AH}^{+}$. Identical parameters were used for recording the analyte spectra 
Figure $4 \mathrm{~b}$ and SI Figure 6b. However, the isotopic patterns reveal an increase in intensity of the isotope peaks marked by horizontal lines due to overlapping deuteronated analytes [A + $\mathrm{D}]^{+}$. Therefore, both analyte ionization processes, Lucky Survivor and gas phase protonation (noticeable as deuteronation), occur. In the case of the CHCA matrix, the vast majority of the ionized analytes are generated according to the Lucky Survivor model, which is responsible for about $90 \%$ of the overall analyte ions calculated by means of the respective peak areas. Using the ClCCA matrix with a lower proton affinity $[28,63-65]$ results in a more efficient proton transfer reaction of $[\mathrm{ma}+\mathrm{H}]^{+}$or deuteron transfer reaction in the case of $[\mathrm{ma}+\mathrm{D}]^{+}$to the neutral analyte, see Figure $4 \mathrm{c}$ and SI Figure $6 \mathrm{c}$. The observation also proves that the ratio between Lucky Survivor and gas phase protonation is strongly affected by the matrix proton affinity. The lower the proton affinity of the matrix, the higher is the percentage of the gas phase protonation of the overall analyte ionization.

One can argue that according to line 3 of Scheme 1, a more reactive matrix with a higher proton and deuteron transfer efficiency should also favor counterion neutralization of the precharged analyte $[\mathrm{A}+\mathrm{H}]^{+}$leading not only to an increase in gas phase protonation but also of the Lucky Survivor process. Although this might be true for anions of very strong acids, neutralization of normally involved anions such as, e.g., chloride, trifluoroacetate, or matrix anions is strongly exoergonic, also taking into account an energy barrier to overcome due to coulomb forces between the charges [54]. Consequently, more reactive matrices should not distinctively enhance such processes. The detectability of deuteronated analytes $[\mathrm{A}+\mathrm{D}]^{+}$raises the question of the origin of the neutral analytes required for this purpose. At acidic $\mathrm{pH}$ values, the basic peptide ITITPNK with a pI of 10.1 exists nearly quantitatively as protonated species in solution. Therefore, the detected $[\mathrm{A}+\mathrm{D}]^{+}$intensity cannot be due to deuteronation of the remaining neutral analytes but can only be explained by deuteronation of the pool of neutral analytes generated upon neutralization of precharged $[\mathrm{A}+\mathrm{H}]^{+}$. This possibility will be elucidated in the following.

\section{Neutralization of Precharged Analytes}

According to the postulation of the Lucky Survivor model, the predominant process of analytes incorporated in the matrix crystals as precharged ions should be their neutralization for energetic reasons. Only the fractions that experience incomplete neutralization can remain as detectable ions. To verify this neutralization process as well as to investigate the possible influence of the analyte structure, the glycine monomer $\left(\mathrm{MW}_{\text {neutral, monoisotopic }}=75.03 \mathrm{~g} / \mathrm{mol}\right)$, dimer $\left(\mathrm{MW}_{\text {neutral, }}\right.$ monoisotopic $\left.=132.05 \mathrm{~g} / \mathrm{mol}\right)$, and hexamer

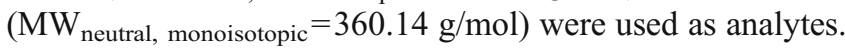
All three analytes exhibit an isoelectric point of $\mathrm{pI}=6$ [62] and were, thus, nearly quantitatively protonated upon addition of $0.1 \%$ TFA to the sample solutions. For the spectra in Figure 5a, the three analytes were investigated using the undeuterated matrix CHCA-tert-butylester. At these conditions, only the protonated analytes $[\mathrm{A}+\mathrm{H}]^{+}$are generated with their respective isotope patterns. In the case the deuterated matrix counterpart CHCA-tert-butylester-d9 is used, the expected protonated and deuteronated analytes can be detected, as shown in Figure 5b. This was already demonstrated for the peptides ITITPNK and ITITPNV and can be explained by parallel Lucky Survivor and gas phase deuteronation processes. A comparison of the deuteronation efficiencies of the three analytes by means of the respective $[\mathrm{A}+\mathrm{D}]^{+} /[\mathrm{A}+\mathrm{H}]^{+}$ratios reveals that with increasing peptide length the intensity of the deuteronated analytes drops. In the case of the glycine hexamer, the first isotope peak at $m / z=362.15$ predominantly is composed of the ${ }^{13} \mathrm{C}$-isotope peak of $[\mathrm{A}+\mathrm{H}]^{+}$and only to a small amount of $[\mathrm{A}+\mathrm{D}]^{+}$. At a first glance, this might be surprising since the analyte collision cross sections rise with increasing length. Together with an also increasing number of protonable amide backbone functionalities one could expect more efficient $[\mathrm{A}+\mathrm{D}]^{+}$ generation. The proton affinities of both glycine amino terminus and amide backbone are very close to each other $(886.2 \mathrm{~kJ} / \mathrm{mol}$ and $889.9 \mathrm{~kJ} / \mathrm{mol}$, respectively $[39,43])$ and are much higher than that of CHCA with $841 \mathrm{~kJ} / \mathrm{mol}$ [35]. Consequently, the basicity of the respective proton acceptor groups cannot be responsible for the detected differences in $[\mathrm{A}+\mathrm{D}]^{+}$generation. It is known that the proton affinity rises with increasing peptide length due to intramolecular stabilization by charge self-solvation $[66,67]$, which leads to clearly higher proton affinities for the larger glycine analytes compared with the glycine monomer [39, 40]. Therefore, intramolecular stabilizations would cause more intense $[\mathrm{A}+\mathrm{D}]^{+}$generation for the larger glycine analytes, which was not observed. This can be explained by the fact that rearrangement timescales are in the range of $\approx 100 \mathrm{~ns}$ ( $\alpha$-helices) to $\approx 6 \mu$ s ( $\beta$-turns) for secondary structure formation [68-71] and about 50-100 $\mu$ s for tertiary contacts $[69,72]$. Thus, they are much too slow for influencing the gas phase protonation/deuteronation process, which happens within the first few tens of nanoseconds after laser irradiation, while most of the collisions between matrix and analyte neutrals and ions occur as is obvious by analyte ion generation in the linear ion mode without delayed extraction.

Therefore, the only reasonable explanation for the decreasing $[\mathrm{A}+\mathrm{D}]^{+}$amounts in the cases of the glycine dimer and hexamer are likewise decreasing amounts of the corresponding deuteronable neutral analytes. As was discussed for the gas phase, intramolecular peptide and protein folding upon analyte protonation during incorporation in the matrix crystal or already in solution can stabilize the protonated ions. Consequently, more stable $[\mathrm{A}+\mathrm{H}]^{+}$ions such as the protonated glycine hexamer will have a higher probability to survive, which means they should undergo a more efficient Lucky Survivor process compared with less stable [glycine $+\mathrm{H}]^{+}$. Therefore, the neutralized analyte amounts of the glycine dimer and especially hexamer will be 

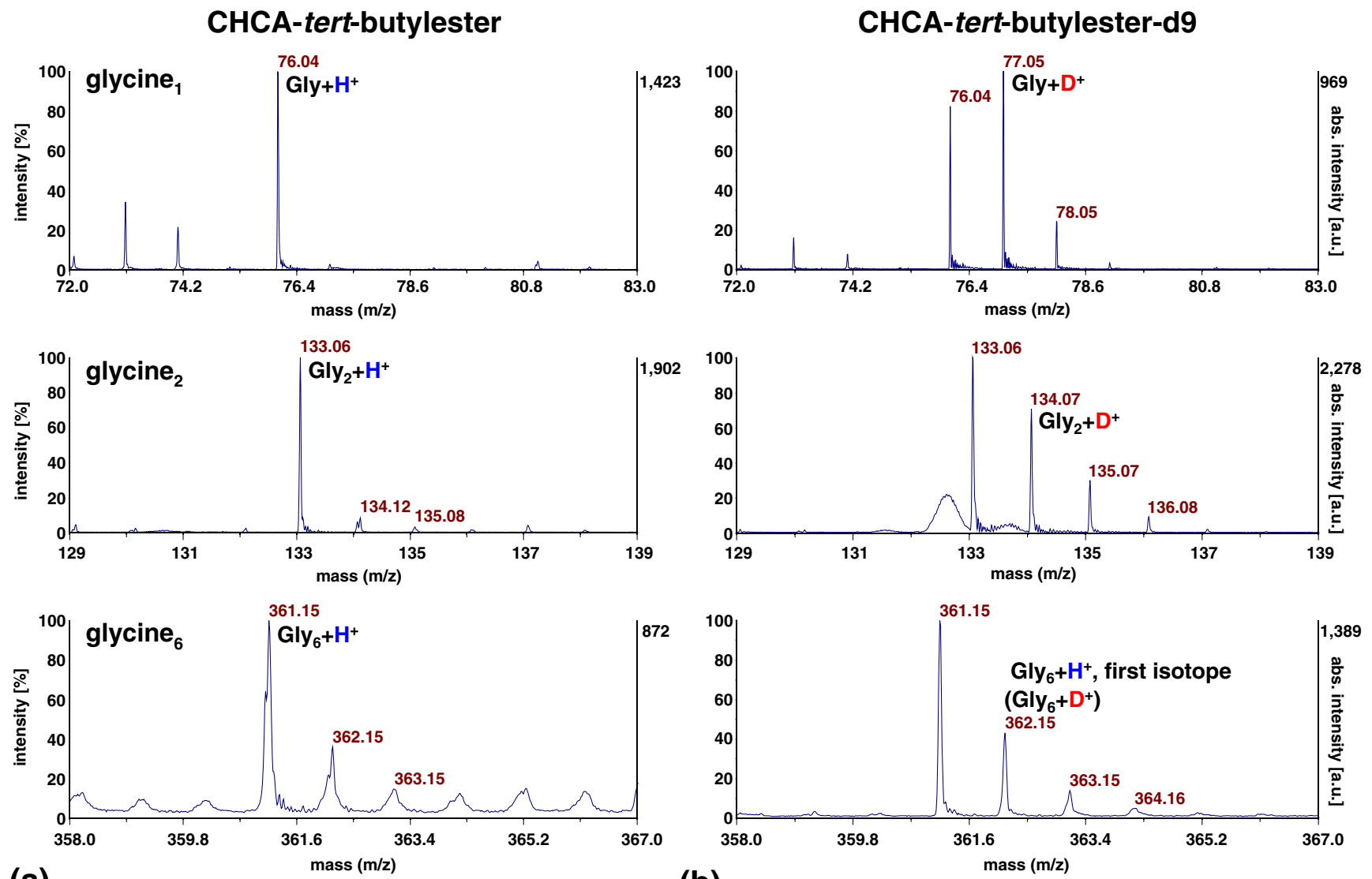

(b)

Figure 5. Isotopic patterns of the protonated glycine monomer, dimer, and hexamer using (a) the undeuterated matrix CHCAtert-butylester and intensities of the protonated and deuteronated signals of the glycine monomer, dimer, and hexamer using (b) the deuterated matrix CHCA-tert-butylester-d9. The low-resolved signal in the deuterated glycine dimer spectrum refers to a CHCA-tert-butylester-d9 fragment generated by PSD fragmentation

lower, which results in only low gas phase deuteronation intensities. Vice versa, less stable protonated glycine undergoes a more efficient neutralization leading to a higher probability for subsequent gas phase deuteronation.

In summary and in addition to the effects discussed in the chapter "Medium Basic Analytes A / $[\mathrm{A}+\mathrm{H}]^{+}$", the efficiency of the Lucky Survivor further depends on the ability of the precharged analytes to stabilize their charge and therefore on their respective size and composition. This reflects the common experience that larger [73] and more basic analytes [74-76] exhibit higher ion yields.

\section{Alternative Explanation Possibilities for Generation of Deuteronated Analytes $[A+D]^{+}$}

Deuteronation of the neutral analytes p-anisaldehyde and 4'hydroxyacetophenone clearly proves the existence of gas phase deuteronation. However, H/D-exchange reactions of $[\mathrm{A}+\mathrm{H}]^{+}$with deuterated matrices might also account for generation of $[\mathrm{A}+\mathrm{D}]^{+}$. Conversion of $[\mathrm{A}+\mathrm{H}]^{+}$to $[\mathrm{A}+\mathrm{D}]^{+}$ upon collision with neutral deuterated matrix esters seems to be improbable because of their stable $\mathrm{C}-\mathrm{D}$ bonds. Therefore, only collisions of $[\mathrm{A}+\mathrm{H}]^{+}$with neutral deuterated matrix acids generated upon ester cleavage seem to be able to generate $[\mathrm{A}+\mathrm{D}]^{+}$. Gas phase backbone H/D exchanges can lead to multiply deuterated analytes, causing broadening or complete shifting of the isotope pattern [77-79]. Nevertheless, the vast majority of the deuteronated analytes exhibit attachment of only one deuteron, which does not reflect the possibility of multiple H/D exchanges but is in accordance with the result of gas phase deuteronations (compare Figures 3, 4 and 5). Additionally, no D/H exchanges have been observed in the case of the deuteronated analytes p-anisaldehyde and 4'-hydroxyacetophenone with the hydrogen of the CHCA-tert-butylester-d9 hydroxyl group which contradicts efficient H/D-plume exchanges, see Figure 2 and SI Figure 4. Application of ClCCA-tert-butylester-d9 and its deuteronated fragmentation product $[\mathrm{ClCCA}-\mathrm{COOD}+\mathrm{D}]^{+}$ increase the analyte deuteronation efficiency compared with the CHCA-counterpart, as shown in Figure 4 and SI Figure 6. This cannot be explained by more efficient H/D-exchanges of protonated analytes since ClCCA is more acidic than CHCA [28] and the exchange rates decrease with reagent acidity $[77,80]$. It is, however, in accordance with a higher deuteron transfer capability due to the lower proton affinity of ClCCA [28, 60, 63]. Further, taking into account that 
glycine hexamers produce less $[\mathrm{A}+\mathrm{D}]^{+}$than the shorter glycine analytes, even though they exhibit a larger collision cross-section and, therefore, should undergo more efficient $\mathrm{H} / \mathrm{D}$-exchanges, it can be concluded that the amount of $[\mathrm{A}+\mathrm{D}]^{+}$generated upon $\mathrm{H} / \mathrm{D}$ exchanges of protonated analytes is low.

\section{The Unified MALDI Analyte Protonation Mechanism}

Based on previously discussed results, which proved the correctness of the Lucky Survivor as well as the gas phase protonation process, a unified MALDI analyte protonation mechanism was created. A simplified version with restriction to positively precharged analyte ions such as peptides and proteins is given in Figure 6. According to the Lucky Survivor model, positively charged clusters release protonated analyte ions $[\mathrm{A}+\mathrm{H}]^{+}$upon dissociation either by lacking anions of preformed analyte ions or more likely by anion neutralization with participation of additionally incorporated $[\mathrm{ma}+\mathrm{H}]^{+}$. The surviving analyte charge originates from solution and is, therefore, initially localized on a basic analyte functional group, which was protonated during sample preparation. Subsequent liberation to the amide backbone according to the mobile proton model becomes possible after ion activation [81-83]. In the case of net neutral clusters, complete charge neutralization occurs upon dissociation releasing neutral A. Proton transfer reactions from $[\mathrm{ma}+\mathrm{H}]^{+}$can protonate the analytes according to the gas phase protonation model. In dependence on the analyte composition and conformation, amide backbones exhibit the highest probability for direct proton attachment. Which of the two protonation pathways dominates depends on parameters such as, e.g., laser fluence, matrix (and analyte) proton affinity, analyte composition and size, and the protonated-to-neutral analyte ratio $[\mathrm{A}+\mathrm{H}]^{+} / \mathrm{A}$ embedded in the matrix crystal.

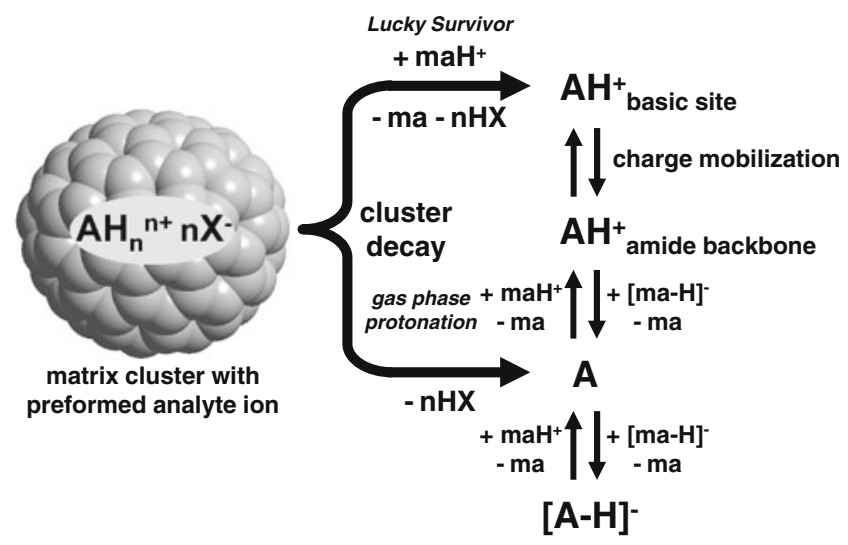

Figure 6. The Unified MALDI Analyte Protonation Mechanism simplified to positively precharged analyte ions. The mechanism combines and connects the Lucky Survivor and the gas phase protonation model
As emphasized in the chapter "Neutralization of Precharged Analytes," the proton affinities of the aminoterminus and of the amide backbone as least basic proton acceptors are still much higher than that of common matrices. Therefore, subsequent neutralizations of protonated analytes are possible only with deprotonated ions such as, e.g., $[\mathrm{ma}-\mathrm{H}]^{-}$. Consequently, it appears unlikely that the generation of deprotonated analyte ions $[\mathrm{A}-\mathrm{H}]^{-}$occurs according to the Lucky Survivor process of positively precharged analytes, which necessitates 2-fold analyte deprotonation with participation of $[\mathrm{ma}-\mathrm{H}]^{-}$but rather to deprotonation of neutral analytes resulting from charge neutralization upon cluster decay, see Figure 6. The gas phase basicities of deprotonated $\alpha$-amino acids [38] are clearly higher than that of the CHCA matrix anion [35], which leads to endergonic analyte deprotonation according to the equilibrium model for charge transfer between matrix and analyte ions [5, 44]. In addition to this, the assumed exclusion of the important Lucky Survivor pathway for $[\mathrm{A}-\mathrm{H}]^{-}$generation further substantiates the positive/negative analyte ion yield ratio $>1$ typically achieved with acidic matrices [26, 49].

\section{Conclusions}

The two long since postulated MALDI analyte protonation pathways known as the Lucky Survivor and the gas phase protonation model could both finally be experimentally proven. Several parameters favoring either the Lucky Survivor or the gas phase protonation were detected and investigated in detail. In addition to laser fluence, matrix and analyte proton affinity and the protonated-to-neutral analyte ratio embedded in the matrix crystal also the analyte composition and size affects the protonation pathway. With increasing size, the investigated peptides were preferably protonated according to the Lucky Survivor mechanism. We ascribe this to more pronounced intramolecular foldings of larger analytes during incorporation in the matrix crystal or already in solution going along with higher survival probabilities of the intramolecular solvated precharged species. It can be expected that for the same reason the survival probabilities of larger precharged peptides and proteins are even higher. In the case of the commonly used matrix CHCA or its deuterated counterpart, respectively, the investigated peptide analytes were ionized to about $90 \%$ according to the Lucky Survivor process. However, the efficiency of the gas phase protonation process strongly increases by using more reactive matrices with lower proton affinities such as ClCCA. Under these conditions, both protonation pathways exhibited nearly same probabilities. The detection of protonated analyte ions in cases of deuterated matrices without any exchangeable hydrogens confirmed the previously claimed incorporation of analytes in their respective solution charge states [52-54].

In a way, it could be expected that both postulated ionization pathways are true, taking into account the multi- 
tude of investigations regarding these models. Consequently, it stands to reason that both Lucky Survivor and gas phase protonation are parts of one greater overall mechanism, which we tried to account for with the presented Unified MALDI Analyte Protonation Mechanism. Therefore, this work finally ends a long-lasting discussion about how at least a partial aspect of one of the most important techniques in current molecular analysis works.

\section{Acknowledgments}

The use of halogenated MALDI matrices is subject of a German patent and international patent application.

The authors acknowledge financial support from the WI Bank for economic and public infrastructure development.

\section{References}

1. Karas, M., Bachmann, D., Hillenkamp, F.: The influence of the wavelength in high irradiance ultraviolet laser desorption mass spectrometry of organic molecules. Anal. Chem. 57, 2935-2939 (1985)

2. Karas, M., Bachmann, D., Bahr, U., Hillenkamp, F.: Matrix-assisted ultraviolet laser desorption of nonvolatile compounds. Int. J. Mass Spectrom. Ion Processes 78, 53-68 (1987)

3. Karas, M., Hillenkamp, F.: Laser desorption ionization of proteins with molecular masses exceeding 10, 000 daltons. Anal. Chem. 60, 22992301 (1987)

4. Hillenkamp, F., Karas, M., Beavis, R.C., Chait, B.T.: Matrix assisted laser desorption/ionization mass spectrometry of biopolymers. Anal. Chem. 63, 1193A-1202A (1991)

5. Ehring, H., Karas, M., Hillenkamp, F.: Role of photoionization and photochemistry in ionization processes of organic molecules and relevance for matrix-assisted laser desorption/ionization mass spectrometry. Org. Mass Spectrom. 27, 472-480 (1992)

6. Spengler, B., Bökelmann, V.: Angular and time resolved intensity distributions of laser-desorbed matrix ions. Nucl Instrum Meth B 82, 379-385 (1993)

7. Bökelmann, V., Spengler, B., Kaufmann, R.: Dynamical parameters of ion ejection and ion formation in matrix-assisted laser desorption/ ionization. Eur. Mass Spectrom. 1, 81-93 (1995)

8. Lia, P.-C., Allison, J.: Ionization processes in matrix-assisted laser desorption/ionization mass spectrometry: matrix-dependent formation of $[\mathrm{M}+\mathrm{H}]^{+}$versus $[\mathrm{M}+\mathrm{Na}]^{+}$ions of small peptides and some mechanistic comments. J. Mass Spectrom. 30, 408-423 (1995)

9. Grigorean, G., Carey, R.I., Amster, I.J.: Studies of exchangeable protons in the matrix-assisted laser desorption/ionization process. Eur. Mass Spectrom. 2, 139-143 (1996)

10. Lehmann, E., Knochenmuss, R., Zenobi, R.: Ionization mechanisms in matrix-assisted laser desorption/ionization mass spectrometry: contribution of preformed ions. Rapid Commun. Mass Spectrom. 11, 1483-1492 (1997)

11. Wong, C.K.L., So, M.P., Chan, T.-W.D.: Origins of the proton in the generation of protonated polymers and peptides in matrix-assisted laser desorption/ionization. Eur. Mass Spectrom. 4, 223-232 (1998)

12. Karbach, V., Knochenmuss, R.: Do single matrix molecules generate primary ions in ultraviolet matrix-assisted laser desorption/ionization. Rapid Commun. Mass Spectrom. 12, 968-974 (1998)

13. McCarley, T.D., McCarley, R.L., Limbach, P.A.: Electron-transfer ionization in matrix-assisted laser desorption/ionization mass spectrometry. Anal. Chem. 70, 4376-4379 (1998)

14. Land, C.M., Kinsel, G.R.: Investigation of the mechanism of intracluster proton transfer from sinapinic acid to biomolecular analytes. $J$. Am. Soc. Mass Spectrom. 9, 1060-1067 (1998)

15. Knochenmuss, R., Karbach, V., Wiesli, U., Breuker, K., Zenobi, R.: The matrix suppression effect in matrix-assisted laser desorption/ ionization: application to negative ions and further characteristics. Rapid Commun. Mass Spectrom. 12, 529-534 (1998)
16. Zenobi, R., Knochenmuss, R.: Ion formation in MALDI mass spectrometry. Mass Spectrom. Rev. 17, 337-366 (1998)

17. Karas, M., Glückmann, M., Schäfer, J.: Ionization in matrix-assisted laser desorption/ionization: singly charged molecular ions are the lucky survivors. J. Mass Spectrom. 35, 1-12 (2000)

18. Frankevich, V., Knochenmuss, R., Zenobi, R.: The origins of electrons in MALDI and their use for sympathetic cooling of negative ions in FTICR. Int. J. Mass Spectrom. 220, 11-19 (2002)

19. Breuker, K., Knochenmuss, R., Zhang, J., Stortelder, A., Zenobi, R.: Thermodynamic control of final ion distributions in MALDI: in-plume proton transfer reactions. Int. J. Mass Spectrom. 226, 211-222 (2003)

20. Karas, M., Krüger, R.: Ion formation in MALDI: the cluster ionization mechanism. Chem. Rev. 103, 427-439 (2003)

21. Dreisewerd, K.: The desorption process in MALDI. Chem. Rev. 103, 395-425 (2003)

22. Fournier, I., Marinach, C., Tabet, J.C., Bolbach, G.: Irradiation effects in MALDI, ablation, ion production, and surface modifications. part III. 2, 5-Dihydroxybenzoic acid Monocrystals. J. Am. Soc. Mass Spectrom. 14, 893-899 (2003)

23. Syage, J.A.: Mechanism of $[\mathrm{M}+\mathrm{H}]^{+}$formation in photoionization mass spectrometry. J. Am. Soc. Mass Spectrom. 15, 1521-1533 (2004)

24. Knochenmuss, R.: Ion formation mechanisms in UV-MALDI. Analyst 131, 966-986 (2006)

25. Meyer, M.A.R., Adams, N., Schubert, U.S.: Statistical approach to understand MALDI-TOF MS matrices: discovery and evaluation of new MALDI matrices. Anal. Chem. 79, 863-869 (2007)

26. Dashtiev, M., Wäfler, E., Röhling, U., Gorshkov, M., Hillenkamp, F., Zenobi, R.: Positive and negative ion yield in matrix-assisted laser desorption/ionization. Int. J. Mass Spectrom. 268, 122-130 (2007)

27. Chang, W.C., Huang, L.C.L., Wang, Y.-S., Peng, W.-P., Chang, H.C., Hsu, N.Y., Yang, W.B., Chen, C.H.: Matrix-Assisted Laser Desorption/ Ionization (MALDI) mechanism revisited. Anal. Chim. Acta 582, 1-9 (2007)

28. Jaskolla, T.W., Lehmann, W.-D., Karas, M.: 4-Chloro- $\alpha$-cyanocinnamic acid is an advanced, rationally designed MALDI matrix. Proc. Natl. Acad. Sci. U. S. A. 105, 12200-12205 (2008)

29. Steenvoorden, R.J.J.M., Breuker, K., Zenobi, R.: The gas-phase basicities of matrix-assisted laser desorption/ionization matrices. Eur. Mass Spectrom. 3, 339-346 (1997)

30. Burton, R.D., Watson, C.H., Eyler, J.R., Lang, G.L., Powell, D.H., Avery, M.Y.: Proton affinities of eight matrices used for matrix-assisted laser desorption/ionization. Rapid Commun. Mass Spectrom. 11, 443446 (1997)

31. Jørgensen, T.J.D., Bojesen, G., Rahbek-Nielsen, H.: The proton affinities of seven matrix-assisted laser desorption/ionization matrices correlated with the formation of multiply charged ions. Eur. J. Mass Spectrom. 4, 39-45 (1998)

32. Breuker, K., Knochenmuss, R., Zenobi, R.: Gas-phase basicities of deprotonated matrix-assisted laser desorption/ionization matrix molecules. Int. J. Mass Spectrom. 184, 25-38 (1999)

33. Mormann, M., Bashir, S., Derrick, P.J., Kuck, D.: Gas-phase basicities of the isomeric dihydroxybenzoic acids and gas-phase acidities of their radical cations. J. Am. Soc. Mass Spectrom. 11, 544-552 (2000)

34. Zhang, J., Knochenmuss, R., Stevenson, E., Zenobi, R.: The gas-phase sodium basicities of common matrix-assisted laser desorption/ionization matrices. Int. J. Mass Spectrom. 213, 237-250 (2002)

35. Mirza, S.P., Raju, N.P., Vairamani, M.: Estimation of proton affinity values of 15 matrix-assisted laser desorption/ionization matrices under electrospray conditions using the kinetic method. J. Am. Soc. Mass Spectrom. 15, 431-453 (2004)

36. Lippa, T.P., Eustis, S.N., Wang, D., Bowen, K.H.: Electrophilic properties of common MALDI matrix molecules. Int. J. Mass Spectrom. 268, 1-7 (2007)

37. Gorman, G.S., Speir, J.P., Turner, C.A., Amster, I.J.: Proton affinities of the 20 common $\alpha$-amino acids. J. Am. Soc. Mass Spectrom. 114, 39863988 (1992)

38. O'Hair, R.A.J., Bowie, J.H., Gronert, S.: Gas phase acidities of the $\alpha$ amino acids. Int. J. Mass Spectrom. Ion Processes 117, 23-36 (1992)

39. Wu, Z., Fenselau, C.: Structural determinants of gas phase basicities of peptides. Tetrahedron 49, 9197-9206 (1993)

40. Wu, Z., Fenselau, C.: Proton affinity of arginine measured by the kinetic approach. Rapid Commun. Mass Spectrom. 6, 403-405 (1992) 
41. Zhang, X., Cassady, C.J.: Apparent gas-phase acidities of multiply protonated peptide ions: ubiquitin, insulin B, and renin substrate. J. Am. Soc. Mass Spectrom. 7, 1211-1218 (1996)

42. Harrison, A.G.: The gas-phase basicities and proton affinities of amino acids and peptides. Mass Spectrom. Rev. 16, 201-217 (1997)

43. Bleiholder, C., Suhai, S., Paizs, B.: Revising the proton affinity scale of the naturally occurring $\alpha$-amino acids. J. Am. Soc. Mass Spectrom. 17, 1275-1281 (2006)

44. Knochenmuss, R., Stortelder, A., Breuker, K., Zenobi, R.: Secondaryion molecule reactions in matrix-assisted laser desorption/ionization. $J$. Mass Spectrom. 35, 1237-1245 (2000)

45. Bourcier, S., Hoppilliard, Y.: B3LYP DFT Molecular orbital approach, an efficient method to evaluate the thermochemical properties of MALDI matrices. Int. J. Mass Spectrom. 217, 231-244 (2002)

46. Ohanessian, G.: Interaction of MALDI matrix molecules with $\mathrm{Na}^{+}$in the gas phase. Int. J. Mass Spectrom. 219, 577-592 (2002)

47. Yassin, F.H., Marynick, D.S.: Computational estimates of the gas-phase acidities of Dihydroxybenzoic acid radical cations and their corresponding neutral species. J. Mol. Struc. Theochem. 629, 223-235 (2003)

48. Ueno-Noto, K., Marynick, D.S.: A comparative computational study of matrix-peptide interactions in MALDI mass spectrometry: the interaction of four tripeptides with the MALDI Matrices 2,5-Dihydroxybenzoic Acid, $\alpha$-Cyano-4-Hydroxy-Cinnamic Acid, and 3,5Dihydroxybenzoic Acid. Mol. Phys. 107, 777-788 (2009)

49. Hillenkamp, F., Wäfler, E., Jecklin, M.C., Zenobi, R.: Positive and negative ion yield in matrix-assisted laser desorption/ionization revisited. Int. J. Mass Spectrom. 285, 114-119 (2009)

50. Krüger, R., Karas, M.: Ion formation in MALDI: the cluster ionization mechanism. Chem. Rev. 103, 427-439 (2003)

51. Knochenmuss, R., Zenobi, R.: MALDI Ionization: the role of in-plume processes. Chem. Rev. 130, 441-452 (2003)

52. Krüger, R., Pfenninger, A., Fournier, I., Glückmann, M., Karas, M.: Analyte incorporation and ionization in matrix-assisted laser desorption/ ionization visualized by $\mathrm{pH}$ indicator molecule probes. Anal. Chem. 73, 5812-5821 (2001)

53. Friess, S.D., Zenobi, R.: Protein structure information from mass spectrometry? selective titration of arginine residues by sulfonates. $J$. Am. Soc. Mass Spectrom. 12, 810-818 (2001)

54. Krüger, R., Karas, M.: Formation and fate of ion pairs during MALDI analysis: anion adduct generation as an indicative tool to determine ionization processes. J. Am. Soc. Mass Spectrom. 13, 1218-1226 (2002)

55. McCombie, G., Knochenmuss, R.: Enhanced MALDI ionization efficiency at the metal-matrix interface: practical and mechanistic consequences of sample thickness and preparation method. J. Am. Soc. Mass Spectrom. 17, 737-745 (2006)

56. Knochenmuss, R., McCombie, G., Faderl, M.: Ion yields of thin MALDI samples: dependence on matrix and metal substrate and implications for models. J. Phys. Chem. A 110, 12728-12733 (2006)

57. Knochenmuss, R., Dubois, F., Dale, M.J., Zenobi, R.: The matrix suppression effect and ionization mechanisms in matrix-assisted laser desorption/ionization. Rapid Commun. Mass Spectrom. 10, 871-877 (1996)

58. Beavis, R.C., Chaudhary, T., Chait, B.T.: $\alpha$-Cyano-4-Hydroxycinnamic acid as a matrix for matrix-assisted laser desorption mass spectrometry. Org. Mass Spectrom. 27, 156-158 (1992)

59. Neises, B., Steglich, W.: Simple method for the Esterification of carboxylic acids. Angew. Chem. Int. Ed Engl. 17, 522-524 (1978)

60. Jaskolla, T.W., Fuchs, B., Karas, M., Schiller, J.: The New Matrix 4Chloro- $\alpha$-Cyanocinnamic Acid Allows the detection of Phosphatidylethanolamine Chloramines by MALDI-TOF mass spectrometry. $J$. Am. Soc. Mass Spectrom. 20, 867-874 (2009)

61. Finholt, P., Higuchi, T.: Rate studies on the hydrolysis of Niacinamide. J. Pharm. Sci. 51, 655-661 (1962)

62. http://www.innovagen.se/custom-peptide-synthesis/peptide-propertycalculator/peptide-property-calculator.asp

63. Jaskolla, T.W., Papasotiriou, D.G., Karas, M.: Comparison between the matrices $\alpha$-Cyano-4-Hydroxycinnamic Acid and 4-Chloro- $\alpha$-Cyanocinnamic Acid for Trypsin, Chymotrypsin, and Pepsin Digestions by
MALDI-TOF mass spectrometry. J. Proteome Res. 8, 3588-3597 (2009)

64. Papasotiriou, D.G., Jaskolla, T.W., Markoutsa, S., Baeumlisberger, D., Karas, M., Mexer, B.: Peptide mass fingerprinting after less specific ingel proteolysis using MALDI-LTQ-Orbitrap and 4-Chloro- $\alpha$-Cyanocinnamic acid. J. Proteome Res. 9, 2619-2629 (2010)

65. Leszyk, J.D.: Evaluation of the New MALDI Matrix 4-Chloro- $\alpha$ Cyanocinnamic Acid. J. Biomol. Technol. 21, 81-91 (2010)

66. Schnier, P.D., Gross, D.S., Williams, E.R.: Electrostatic forces and dielectric Polarizability of multiply protonated gas-phase Cytochrome $c$ ions probed by ion/molecule chemistry. J. Am. Chem. Soc. 117, 67476757 (1995)

67. Schnier, P.D., Price, W.D., Williams, E.R.: Modeling the maximum charge state of Arginine-containing Peptide ions formed by Electrospray Ionization. J. Am. Soc. Mass Spectrom. 7, 972-976 (1996)

68. Gruebele, M., Sabelko, J., Ballew, R., Ervin, J.: Laser temperature jump induced protein folding. Acc. Chem. Res. 31, 699-707 (1998)

69. Gilmanshin, R., Williams, S., Callender, R.H., Woodruff, W.H., Dyer, R.B.: Fast events in protein folding: relaxation dynamics of secondary and tertiary structure in native Apomyoglobin. Proc. Natl. Acad. Sci. U. S. A. 94, 3709-3713 (1997)

70. Dyer, R.B., Gai, F., Woodruff, W.H., Gilmanshin, R., Callender, R.H.: Infrared studies of fast events in protein folding. Acc. Chem. Res. 31, 709-716 (1998)

71. Freddolino, P.L., Liu, F., Gruebele, M., Schulten, K.: Ten-microsecond molecular dynamics simulation of a fast-folding WW domain. Biophys. J. 94, L75-L77 (2008)

72. Hagen, S.J., Hofrichter, J., Szabo, A., Eaton, W.A.: Diffusion-limited contact formation in unfolded cytochrome $c$ : estimating the maximum rate of protein folding. Proc. Natl. Acad. Sci. U. S. A. 93, 11615-11617 (1996)

73. Beeson, M.D., Murray, K.K., Russell, D.H.: Aeorosol matrix-assisted laser desorption ionization: effects of analyte concentration and matrixto-analyte ratio. Anal. Chem. 67, 1981-1986 (1995)

74. Krause, E., Wenschuh, H., Jungblut, P.R.: The dominance of arginine containing peptides in MALDI-Derived Tryptic mass fingerprints of proteins. Anal. Chem. 71, 4160-4165 (1999)

75. Valero, M.-L.V., Giralt, E., Andreu, D.: An investigation of residuespecific contributions to peptide desorption in MALDI-TOF mass spectrometry. Lett. Pept. Sci. 6, 109-115 (1999)

76. Baumgart, S., Lindner, Y., Kühne, R., Oberemm, A., Wenschuh, H., Krause, E.: The contributions of specific amino acid side chains to signal intensities of peptides in matrix-assisted laser desorption/ionization mass spectrometry. Rapid Commun. Mass Spectrom. 18, 863-868 (2004)

77. Campbell, S., Rodgers, M.T., Marzluff, E.M., Beauchamp, J.L.: Structural and energetic constraints on gas phase hydrogen/deuterium exchange reactions of protonated peptides with $\mathrm{D}_{2} \mathrm{O}, \mathrm{CD}_{3} \mathrm{OD}$, $\mathrm{CD}_{3} \mathrm{CO}_{2} \mathrm{D}$, and $\mathrm{ND}_{3}$. J. Am. Chem. Soc. 116, 9765-9766 (1994)

78. Wyttenbach, T., Bowers, M.T.: Gas phase conformations of biological molecules: the hydrogen/deuterium exchange mechanism. J. Am. Soc. Mass Spectrom. 10, 9-14 (1999)

79. He, F., Marshall, A.G.: Assignment of gas-phase dipeptide amide hydrogen exchange rate constants by site-specific substitution: GlyGly. J. Phys. Chem. B 105, 2244-2249 (2001)

80. Campbell, S., Rodgers, M.T., Marzluff, E.M., Beauchamp, J.L.: Deuterium exchange reactions as a probe of biomolecule structure. fundamental studies of gas phase $\mathrm{H} / \mathrm{D}$ exchange reactions of protonated glycine oligomers with $\mathrm{D}_{2} \mathrm{O}, \mathrm{CD}_{3} \mathrm{OD}, \mathrm{CD}_{3} \mathrm{CO}_{2} \mathrm{D}$, and $\mathrm{ND}_{3} . J . A m$. Chem. Soc. 117, 12840-12854 (1995)

81. Wysocki, V.H., Tsaprailis, G., Smith, L.L., Breci, L.A.: Mobile and localized protons: a framework for understanding peptide dissociation. J. Mass Spectrom. 35, 1399-1406 (2000)

82. Wysocki, V. H.; Cheng, G.; Zhang, Q.; Hermann, K. A.; Beardsley, R. L.; Hilderbrand, A. E. Peptide Fragmentation Overview. In Principles of Mass Spectrometry Applied to Biomolecules; Laskin, J.; Lifshitz, C., Eds.; John Wiley and Sons: Hoboken, NJ, 2006; Chap VIII, pp. 279-300.

83. Boyd, R., Somogyi, Á.: The mobile proton hypothesis in fragmentation of protonated peptides: a perspective. J. Am. Soc. Mass Spectrom. 21, 1275-1278 (2010) 